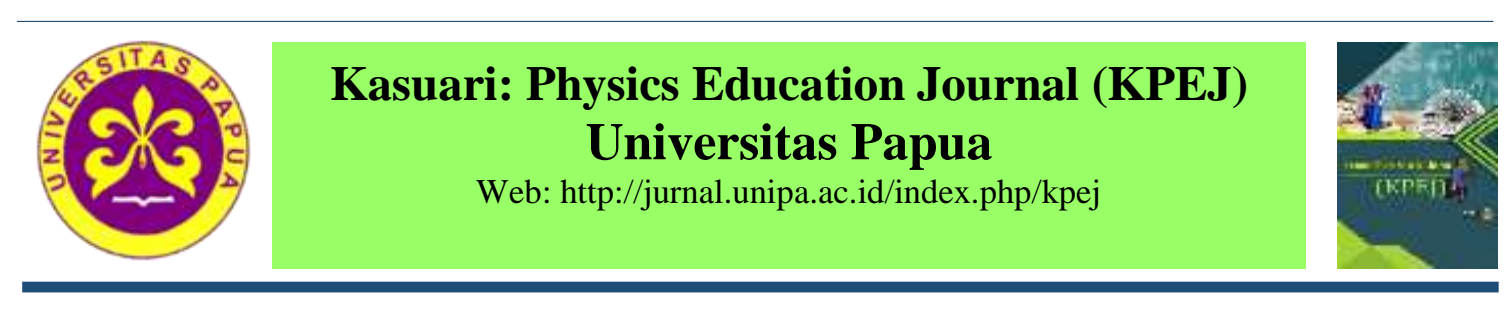

\title{
Analysis of Students' Critical Thinking Skills on Solid Material Elasticity
}

\author{
Surya Haryandi*, Misbah, Mastuang, Dewi Dewantara, \& Saiyidah Mahtari \\ Program Studi Pendidikan Fisika, Universitas Papua \\ *surya.haryandi@ulm.ac.id
}

\begin{abstract}
The research aims to analyze students' critical thinking skills (CTS). This type of research is descriptive qualitative. The research subjects consisted of 31 students of Class XI MIPA in one of the high schools in the city of Banjarmasin. The instrument is in the form of 6 CTS test items that measure 2 subindicators, namely drawing conclusions from the results of investigating and evaluating (formulating alternative solutions). Descriptive data analysis by describing CTS on the two sub-indicators. The results showed that the CTS of students at this time were still in the low category, which was marked from the percentage of 2 CTS sub-indicators namely drawing conclusions from the results of investigating and evaluating (formulating alternative solutions) which was still low under 10\%. Further research needs to be done on CTS which is allegedly capable of being trained through an inquiry model based worksheets.
\end{abstract}

Keywords: critical thinking skills, worksheets, \& inquiry

\section{Analisis Keterampilan Berpikir Kritis Peserta Didik pada Materi Elastisitas Zat Padat}

\begin{abstract}
Abstrak: Penelitian bertujuan untuk menganalisis keterampilan berpikir kritis (KBK) peserta didik. Jenis penelitian adalah deskriptif kualitatif. Subjek penelitian terdiri dari 31 peserta didik kelas XI MIPA pada salah satu SMA di kota Banjarmasin. Instrumen berupa 6 butir soal tes KBK yang mengukur 2 sub indikator yaitu menarik kesimpulan dari hasil menyelidiki dan melakukan evaluasi (merumuskan solusi alternatif). Analisis data secara deskriptif dengan mendeskripsikan KBK pada dua sub indikator tersebut. Hasil penelitian menunjukkan bahwa KBK peserta didik saat ini masih pada kategori rendah, yang ditandai dari persentase 2 sub indikator KBK yaitu menarik kesimpulan dari hasil menyelidiki dan melakukan evaluasi (merumuskan solusi alternatif) yang masih rendah di bawah 10\%. Perlu dilakukan penelitian lanjutan terkait KBK yang diduga kuat mampu dilatih melalui LKPD berbasis model inquiry.
\end{abstract}

Kata kunci: keterampilan berpikir kritis, LKPD, \& Inquiry

\section{PENDAHULUAN}

Memasuki abad ke-21 ditandai dengan perubahan yang sangat signifikan dalam dunia teknologi, informasi, komunikasi, perekonomian, kesehatan, dan tidak luput juga dalam dunia pendidikan. Sekolah sebagai institusi pendidikan memiliki kurikulum dan desain pembelajaran yang berperan sangat penting untuk mencetak generasi penerus dengan pengalaman pendidikan yang mampu bertahan dan mengarungi derasnya arus globlisasi (Kids, 2019). Oleh karena itu, institusi pendidikan seyogyanya membekali calon generasi penerus dengan keterampilan-keterampilan abad ke-21.

Euforia abad ke-21 tidak hanya sampai disini melainkan ditambah dengan masuknya era revolusi industri 4.0 yang menandai pesatnya perkembangan dunia dalam segala aspek khususnya teknologi, informasi, dan komunikasi (TIK). Ibarat belati bermata dua, pesatnya perkembangan dunia dapat membawa pengaruh positif dan dapat pula 
membawa pengaruh negatif. Adanya kedua momentum besar ini memberikan konsekuensi besar pula bagi dunia pendidikan. Institusi pendidikan dituntut agar membekali lulusannya dengan keterampilan-keterampilan khusus karena lapangan kerja pada abad ke-21 dan era revolusi industri 4.0 bersifat digital, berkurangnya tenaga kerja fisik, analisis informasi, multikultural, dan saling berhubungan dalam jejaring sosial (Zubaidah, 2016).

Setidaknya ada empat kompetensi yang harus dimiliki peserta didik di abad ke-21 ini yang sering disebut 4C yaitu Critical Thinking and Problem Solving, Creativity, Communication Skills, dan Ability to Work Collaboratively (Kemdikbud, 2017; Wasis, 2016). Critical Thinking atau berpikir kritis merupakan salah satu aspek dari 4C yang penting untuk dilatihkan kepada peserta didik. Berpikir kritis membuat peserta didik mampu menarik kesimpulan, merefleksi, dan mengambil keputusan secara sadar dan bijak (Brookhart, 2010). Melalui berpikir kritis peserta didik diajak melihat suatu informasi dari sudut pandang berbeda agar dapat membuat penilaian atau kesimpulan terbaik (Negoro, Hidayah, Rusilowati, \& Subali, 2018; Nurazizah, Sinaga, \& Jauhari, 2017; Sarwi, Rusilowati, \& Khanafiyah, 2013a).

Berpikir kritis merupakan salah satu keterampilan berpikir tingkat tinggi. Keterampilan Berpikir Kritis (KBK) tidak bisa diperoleh secara singkat melainkan harus dilatihkan. Pada umumnya peserta didik yang terlatih untuk berpikir kritis juga memiliki kemampuan analisis yang baik, logika bernalar yang baik, mampu menyeleksi informasi yang diperoleh serta bersikap hati-hati dalam mengambil keputusan (Putra, 2015). Mata pelajaran fisika berfungsi melatih kemampuan berpikir dalam rangka memecahkan masalah nyata dalam kehidupan sehari-hari (Mahtari, Misbah, Hartini, \& Suryati, 2019). Berdasarkan hasil wawancara dengan guru mata pelajaran fisika di salah satu SMAN di kota Banjarmasin, proses pembelajaran yang digunakan masih bersifat konvensional dimana guru membuka pembelajaran lalu memberikan metode ceramah dan memberi pelatihan kepada peserta didik. Selain itu kemampuan berpikir peserta didik seperti keterampilan berpikir kritis, belum dioptimalkan untuk dilatih dalam proses pembelajaran. Hal ini dapat dilihat dari rendahnya hasil belajar peserta didik masih di bawah kriteria ketuntasan minimal (KKM) yaitu 29.35. Padahal keterampilan berpikir merupakan salah satu bagian penting yang harus dimiliki anak di abad 21 ini. Oleh karena itu dilakukan penelitian untuk menganalisis KBK peserta didik kelas XI. Harapannya hasil analisis ini dapat ditindaklanjuti untuk peningkatan kualitas pendidikan kedepannya.

\section{METODE PENELITIAN}

Jenis penelitian berupa deskriptif kualitatif. Subjek terdiri dari 31 peserta didik kelas XI MIPA pada salah satu SMA di kota Banjarmasin. Instrumen yang digunakan berupa tes yang dikembangkan dari indikator KBK yang dapat dilihat pada Tabel 1.

Tabel 1. Dasar Pengembangan Instrumen

\begin{tabular}{|l|l|l|c|}
\hline \multicolumn{1}{|c|}{ Kelompok } & \multicolumn{1}{c|}{ Indikator KBK } & \multicolumn{1}{c|}{ Sub indikator KBK } & Nomor Soal \\
\hline Menyimpulkan & $\begin{array}{l}\text { Menginduksi dan } \\
\text { mempertimbangkan } \\
\text { hasil induksi }\end{array}$ & $\begin{array}{l}\text { Menarik kesimpulan dari } \\
\text { hasil menyelidiki }\end{array}$ & $1,3,5$ \\
\hline $\begin{array}{l}\text { Mengatur } \\
\text { strategi dan } \\
\text { taktik }\end{array}$ & $\begin{array}{l}\text { Menentukan suatu } \\
\text { tindakan }\end{array}$ & $\begin{array}{l}\text { Melakukan evaluasi } \\
\text { (merumuskan solusi } \\
\text { alternatif) }\end{array}$ & $2,4,6$ \\
\hline
\end{tabular}


Instrumen tes dibuat untuk mengukur KBK dari 2 sub indikator yaitu menarik kesimpulan dari hasil menyelidiki dan melakukan evaluasi (merumuskan solusi alternatif). Jumlah soal yang dijabarkan dari 2 sub indikator KBK tersebut ialah sebanyak 6 butir yang kemudian dibagi rata menjadi 3 butir untuk masing-masing sub indikator. Data skor KBK peserta didik yang sudah diperoleh dari tes dicari rerata pencapaiannya terhadap KBK. Data itu selanjutnya dipilah untuk mengetahui berapa persen hasil yang diperoleh dari masing-masing sub indikator. Teknik analisis data dilakukan dengan cara deskriptif yaitu mendeskripsikan KBK pada dua sub indikator tersebut. Kategorisasi data menggunakan formula signifikansi perbedaan yang membagi individu ke dalam jenjang kategori rendah, sedang, dan tinggi (Azwar, 2015; Widhiarso, 2009).

\section{HASIL DAN PEMBAHASAN}

Peneliti menggunakan instrumen tes untuk menggali KBK awal peserta didik. Indikator KBK yang diteliti meliputi menarik kesimpulan dari hasil menyelidiki dan melakukan evaluasi (merumuskan solusi alternatif). Berdasarkan hasil analisis instrumen tes hasil KBK peserta didik dapat dilihat pada Gambar 1.

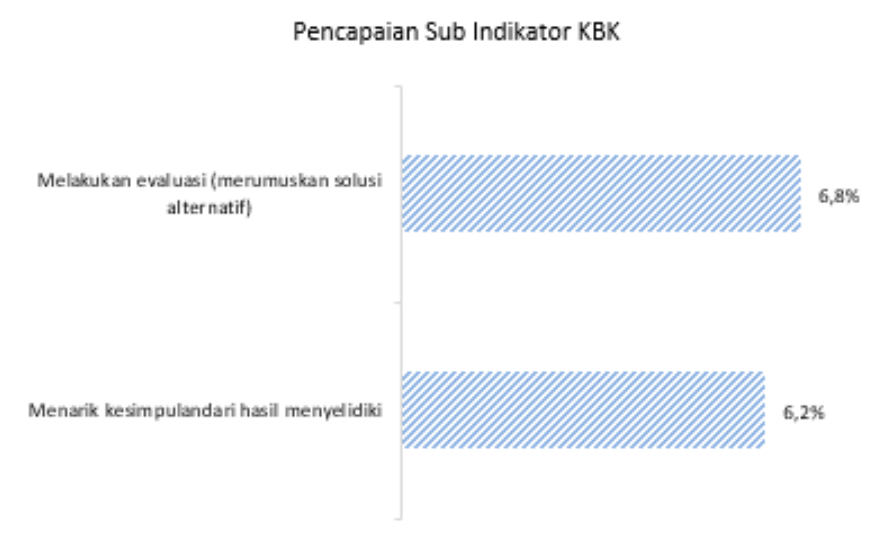

Gambar 1. Pencapaian Sub Indikator KBK

Berdasarkan temuan ini pada masing-masing indikator KBK, pencapaian peserta didik masih berkategori rendah. Rendahnya KBK peserta didik diantaranya disebabkan kurang terlatihnya peserta didik akibat pembelajaran yang cenderung berfokus pada mengingat (C1) dan memahami (C2) (Syalehin, Hartini, \& Suriasa, 2015), kurang seringnya diberikan tugas interaktif yang mampu melatih KBK (Kuzaimah, Wati, \& Hartini, 2014; Misbah, Mahtari, Wati, \& Harto, 2018; Prahani, Jatmiko, Arifin, \& Supardi, 2019) serta proses penilaian yang belum mengakomodir KBK peserta didik (Ngurahrai, Farmaryanti, \& Nurhidayati, 2019).

Pembelajaran fisika tidak dapat dipisahkan dari telaah teori melalui buku-buku sumber dan pembuktian teori melalui praktikum di laboratorium. Memiliki fasilitas penunjang dan laboratorium yang terstandarisasi untuk praktikum merupakan suatu keniscayaan bagi institusi pendidikan khususnya sekolah menengah atas (SMA). Jika kita mengacu pada keterampilan abad ke-21, KBK salah satu kemampuan berpikir tingkat tinggi dan salah satu kompetensi penting dari 4C (Communication, Collaborative, Critical Thinking, and Problem Solving) yang harus dimiliki peserta didik. KBK bukan sifat yang diturunkan secara genetik melainkan harus dilatihkan melalui proses belajar (Widyaningsih \& Yusuf, 2018). Melatih KBK dapat dilakukan dengan melatih kemampuan bernalar yaitu dengan menghadapkan peserta didik pada permasalahan 
kemudian menggali konsep apa saja yang selama ini sudah dikuasai peserta didik untuk menghadapi situasi atau masalah tersebut (Negoro, et al., 2018). Oleh sebab itu, hal inilah yang masih belum dapat dilakukan oleh model konvensional. Peneliti ingin mencoba menganalisis keterampilan berpikir kritis yang ada saat ini dengan model inquiry.

Salah satu model yang dapat digunakan dalam melatih KBK dengan memanfaatkan laboratorium adalah model inquiry. Inquiry berhubungan erat dengan kegiatan penyelidikan ilmiah yakni peserta didik aktif melakukan penyelidikan untuk membangun pemahaman konsep secara mandiri dan terstruktur (Sarwi et al., 2013a). Dalam menjalankan inquiry guru dapat melatih kemampuan penalaran sekaligus kemampuan berpikir kritis peserta didik.

Beberapa penelitian sebelumnya menunjukkan bahwa pembelajaran berbasis inquiry pembelajaran berbasis inquiry lebih efektif dalam meningkatkan kerja sama, percaya diri, karakter disiplin, motivasi, hasil belajar, dan kreativitas peserta didik jika dibandingkan dengan pembelajaran konvensional (Mundilarto, 2013; Yardi, 2015). Pembelajaran sains yang diimplementasikan dengan inquiry terbukti meningkatkan hasil belajar peserta didik (Nasution, 2018; Yunus, Sanjaya, \& Jatmiko, 2013) dan mengembangkan keterampilan komunikasi ilmiah (Sarwi, Rusilowati, \& Khanafiyah, 2013b). Tidak hanya itu, pembelajaran berbasis inquiry juga dapat meningkatkan literasi ilmiah dan KBK (Fuad, Zubaidah, Mahanal, \& Suarsini, 2017; Prayogi, Yuanita, \& Wasis, 2018; Seraphin, Philippoff, Kaupp, \& Vallin, 2012). Berdasarkan hasil tersebut maka peneliti berkeyakinan bahwa KBK peserta didik dapat dilatih melalui model inquiry.

Salah satu upaya untuk melatih kemampuan penalaran dan berpikir kritis yaitu melalui pembelajaran berbasis proyek dalam bentuk inquiry supaya peserta didik sendiri yang membangun pengetahuan dan konsepnya melalui serangkaian kegiatan penyelidikan ilmiah (Artayasa, Susilo, Lestari, \& Indriwati, 2018; Martawijaya, 2015; Sarwi et al., 2013a). Inquiry bertujuan merangsang disiplin intelektual peserta didik melalui pertanyaan, mencari jawaban secara mandiri dan rasa keingintahuan untuk memecahkan masalah (Yardi, 2015).

KBK dapat dikembangkan melalui penerapan berbagai media inovatif yang dikembangkan oleh guru dalam pembelajaran (Yusuf \& Widyaningsih, 2017). Pembelajaran di kelas memerlukan media salah satunya ialah lembar kerja peserta didik (LKPD). Beberapa penelitian memaparkan bahwa LKPD yang dikembangkan secara khusus dapat melatih keterampilan berpikir kritis (Kuzaimah et al., 2014; Suriasa, 2018; Syalehin et al., 2015). LKPD yang dapat melatih KBK ialah yang soal-soalnya memuat beberapa aspek KBK yang bisa diamati seperti 1) Mengenali pernyataan suatu alasan; 2) Mengidentifikasi, mengelompokkan, dan menjawab pertanyaan klarifikasi; 3) Mendeskripsikan sebab dari suatu perbedaan; 4) Menjelaskan secara sederhana; 5) Memberi contoh; 6) Menjawab suatu pernyataan dengan alasan logis; 7) Mengenali asumsi dan memberi argumen (Kuzaimah, et al., 2014). Diharapkan dengan adanya LKPD menggunakan model inquiry dapat melatih KBK peserta didik.

\section{SIMPULAN DAN SARAN}

KBK peserta didik saat ini masih pada kategori rendah, yang ditandai dari persentase 2 sub indikator KBK yaitu menarik kesimpulan dari hasil menyelidiki dan melakukan evaluasi (merumuskan solusi alternatif) yang masih rendah dibawah 10\%. Perlu dilakukan penelitian lanjutan terkait KBK yang diduga kuat mampu dilatih melalui LKPD berbasis model inquiry. 


\section{DAFTAR PUSTAKA}

Artayasa, I. P., Susilo, H., Lestari, U., \& Indriwati, S. E. (2018). The Effect of Three Levels of Inquiry on the Improvement of Science Concept Understanding of Elementary School Teacher Candidates. International Journal of Instruction, 11(2), $235-248$.

Azwar, S. (2015). Penyusunan Skala Psikologi (2nd ed.). Yogyakarta: Pustaka Pelajar.

Brookhart, S. M. (2010). How to Assess Higher-Order Thinking Skills in Your Classroom. In $A S C D$. Alexandria: ASCD.

Fuad, N. M., Zubaidah, S., Mahanal, S., \& Suarsini, E. (2017). Improving Junior High Schools' Critical Thinking Skills Based on Test Three Different Models of Learning. International Journal of Instruction, 10(1), 101-116.

Kemdikbud. (2017). Pendidikan Karakter Dorong Tumbuhnya Kompetensi Siswa Abad 21. Retrieved November 20, 2019, from www.kemdikbud.go.id website: https://www.kemdikbud.go.id/main/blog/2017/06/pendidikan-karakter-dorongtumbuhnya-kompetensi-siswa-abad-21

Kids, B. for. (2019). 21st Century Learning and Assessment Design. Retrieved November 28, 2019, from www.battelleforkids.org website: http://www.battelleforkids.org/how-we-help/learning-design

Kuzaimah, S., Wati, M., \& Hartini, S. (2014). Pengembangan Lembar Kerja Siswa (LKS) dan Media Penunjang untuk Mengaktifkan Keterampilan Berpikir Kritis. Berkala Ilmiah Pendidikan Fisika, 2(2), 133.

Mahtari, S., Misbah, M., Hartini, S., \& Suryati, S. (2019). Analysis of the Ability of High School Students in Solving Science Literacy Questions Based on The Rasch Model. Kasuari: Physics Education Journal, 2(1), 11-16.

Martawijaya, M. A. (2015). Karakter Peserta Didik dan Hubungannya dengan Keterampilan Berpikir Kritis dalam Pembelajaran Fisika Siswa SMP. Journal of EST, 1(2), 1-7.

Misbah, M., Mahtari, S., Wati, M., \& Harto, M. (2018). Analysis of Students ' Critical Thinking Skills In Dynamic Electrical Analisis Keterampilan Berpikir Kritis Siswa Pada Materi Listrik. Kasuari: Physics Education Journal, 1(2), 103-110.

Mundilarto, M. (2013). Keefektifan Pendekatan Inquiry Based Learning untuk Peningkatan Karakter Siswa SMA pada Pembelajaran Fisika. Cakrawala Pendidikan, 32(2), 250-257.

Nasution, W. N. (2018). The Effects of Inquiry-Based Learning Approach and Emotional Intelligence on Students' science achievement levels. Journal of Turkish Science Education, 15(4), 104-115.

Negoro, R. A., Hidayah, H., Rusilowati, A., \& Subali, B. (2018). Upaya Membangun Keterampilan Berpikir Kritis menggunakan Peta Konsep untuk Mereduksi Miskonsepsi Fisika. Jurnal Pendidikan (Teori Dan Praktik), 3(1), 45-51.

Ngurahrai, A. H., Farmaryanti, S. D., \& Nurhidayati, N. (2019). Media Pembelajaran Materi Momentum dan Impuls Berbasis Mobile Learning untuk Meningkatkan Kemampuan Berpikir Kritis Siswa. Berkala Ilmiah Pendidikan Fisika, 7(1), 62-70.

Nurazizah, S., Sinaga, P., \& Jauhari, A. (2017). Profil Kemampuan Kognitif dan Keterampilan Berpikir Kritis Siswa SMA pada Materi Usaha dan Energi. Jurnal Penelitian \& Pengembangan Pendidikan Fisika, 3(2), 197-202.

Prahani, B. K., Jatmiko, B., Arifin, Z., \& Supardi, I. (2019). The Practicality of or-IPA Learning Model to Improve Critical Thinking Skill of Prospective Physics Teachers. Berkala Ilmiah Pendidikan Fisika, 7(3), 148-156.

Prayogi, S., Yuanita, L., \& Wasis. (2018). Critical Inquiry Based Learning : a Model of 
Learning to Promote Critical Thinking among Prospective Teachers of Physic. Journal of Turkish Science Education, 15(1), 43-57.

Putra, M. I. S. (2015). Pembelajaran Fisika dengan Pendekatan Keterampilan Berpikir Kritis Untuk Meningkatkan Hasil Belajar Siswa SMP Unggulan Amanatul Ummah Surabaya. Journal Pedagogia, 4(2), 127-134.

Sarwi, Rusilowati, A., \& Khanafiyah, S. (2013a). Implementasi Model Eksperimen Gelombang Open-Inquiry untuk Mengembangkan Keterampilan Berpikir Kritis Mahasiswa Fisika. Jurnal Pendidikan Fisika Indonesia, 9, 41-50.

Sarwi, S., Rusilowati, A., \& Khanafiyah, S. (2013b). Implementasi Model Eksperimen Gelombang Open-Inquiry untuk Mengembangkan Keterampilan Berpikir Kritis Mahasiswa Fisika. Jurnal Pendidikan Fisika Indonesia, 9(2013), 123-131

Seraphin, K. D., Philippoff, J., Kaupp, L., \& Vallin, L. M. (2012). Metacognition as Means to Increase the Effectiveness of Inquiry-Based Science Education. Science Education International, 23(4), 366-382.

Suriasa, S. (2018). Penerapan Model Pembelajaran Problem Posing Menggunakan LKS Berbasis Scientific Aproach untuk Meningkatkan Keterampilan Berpikir Kritis Siswa. Berkala Ilmiah Pendidikan Fisika, 6(2), 190-204.

Syalehin, M. R., Hartini, S., \& Suriasa. (2015). Pengembangan LKS Berbasis Keterampilan Berpikir Kritis untuk Mendukung Implementasi K13. Berkala Ilmiah Pendidikan Fisika, 3(1), 52-59.

Wasis. (2016). Higher Order Thinking Skills (HOTS): Konsep dan Implementasinya. Assessment of Higher Order Thinking Skills, (1), 10-12. Mataram: Prosiding Seminar Nasional Pusat Kajian Pendidikan Sains dan Matematika (PKPSM).

Widhiarso, W. (2009). Mengkategorikan Data. Yogyakarta.

Widyaningsih, S. W., \& Yusuf, I. (2018). Project Based Learning Model Based on Simple Teaching Tools and Critical Thinking Skills. Kasuari: Physics Education Journal, 1(1), 12-21.

Yardi, Y. (2015). Upaya Peningkatan Motivasi Belajar Siswa dengan Pendekatan Inquiry Pada Pelajaran Fisika Kelas XI Multimedia Semester 1 SMK Negeri 1 Gunung Talang Kabupaten Solok Tahun Pelajaran 2012 / 2013. Jurnal EDUCATIO, 1(1), 53-67.

Yunus, S. R., Sanjaya, I. G. M., \& Jatmiko, B. (2013). Implementasi Pembelajaran Fisika Berbasis Guided Inquiry untuk Meningkatkan Hasil Belajar Siswa Auditorik. Jurnal Pendidikan IPA Indonesia, 2(1), 48-52.

Yusuf, I., \& Widyaningsih, S. W. (2017). Penerapan Laboratorium Virtual pada Mata Kuliah Eksperimen Fisika terhadap Keterampilan Berpikir Kritis Mahasiswa Pendidikan Fisika Universitas Papua. Sainsmat, 6(1), 75-81.

Zubaidah, S. (2016). Keterampilan Abad ke-21: Keterampilan yang Diajarkan Melalui Pembelajaran. Seminar Nasional Pendidikan, 2(2), 1-17. 